\title{
WHOLE-BODY VIBRATION RESPONSE THROUGH THE UPPER LIMBS ASSOCIATED WITH REACHING MOVEMENTS AND POSTURE
}

\author{
Heon-Jeong Kim*,1) and Bernard J. Martin ${ }^{2)}$ \\ ${ }^{1)}$ Department of Mechanical Engineering, University of Michigan \\ ${ }^{2)}$ Department of Industrial and Operations Engineering, University of Michigan
}

\section{Introduction}

Exposure of human operators to whole-body vibration may induce health risks, interfere with manual operation, and compromise tasks performed in a vehicle [Griffin 1990], [Okunribido et al 2007]. For operator's safety and performance enhancement, numerous investigations have attempted to identify the characteristics of WBV responses of seated individuals. WBV responses are functions of vibration variables [Griffin 1990] and postures [Lim et al 2004], [Kim and Bernard 2008]. As opposed to earlier studies involving limited static postures, the present work analyzes human responses for a large range of arm postures including two elbow flexion constraints in reaching movements.

\section{Methods}

Twenty-one participants performed a reaching task on the ride motion simulator of the U.S Army TARDEC, and maintained pointing posture at the end of the reaches for the estimation of WBV transmission. The task consisted of reaching with the right hand seven targets distributed in the right hemisphere of the workspace: upward [TG1], forward-upward [TG2], forward [TG3], forward-lateral [TG4], diagonal-upward [TG5], lateral near [TG6], and lateral far [TG7]. To investigate effects of movement direction and posture on vibration responses of the seated human, all reaches were performed with two postures such as elbow fully extended or flexed (Figure 1). Three vertical vibration conditions with a frequency of 2, 4, and $6 \mathrm{~Hz}$ were selected. Reaching movements and cab perturbations were measured by a VICON motion tracking system and tri-axial accelerometers, respectively.

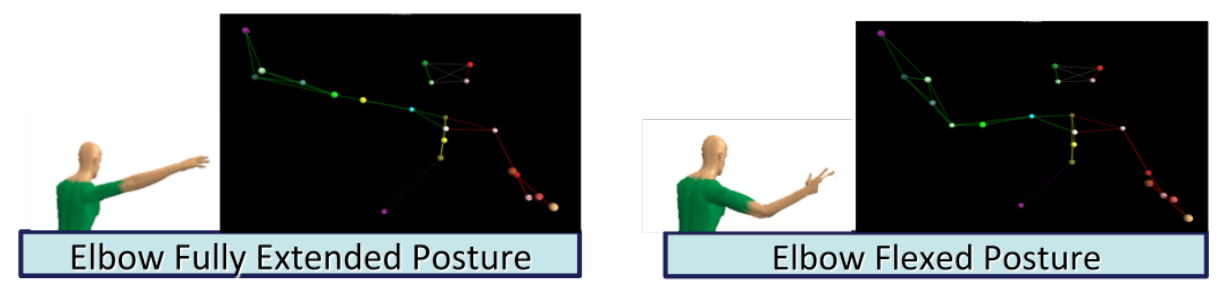

Figure 1: Elbow fully extended and flexed postures used during reaching tasks

\section{Results and Discussion}

WBV responses through the human multi-segment system vary as functions of vibration condition $(\mathrm{p} \approx 0)$, target direction/location $(\mathrm{p}<0.01)$, and elbow joint constraint $(\mathrm{p}<0.01)$. Vibration frequency is the dominant factor affecting WBV responses. The interaction between the movement direction and the vibration direction influences WBV responses for specific vibration frequencies. Furthermore, the full extension of the elbow 
produces small elbow oscillations but contributes an amplification of the finger displacement relative to the elbow, while the elbow flexed posture produces large elbow perturbations but contributes to an attenuation of finger perturbation. In this study, transmission propagated through the upper limb was investigated for vertical sinusoidal vibrations with the selected frequencies only as they correspond to the largest effects. For realistic human motion simulation in vibratory environments, biodynamic characteristics of the seated human under multi-directional vibration inputs may be required to provide a more complete description of whole-body vibration transmissibility and facilitate the implementation of a 3-dimensional biomechanical model development.

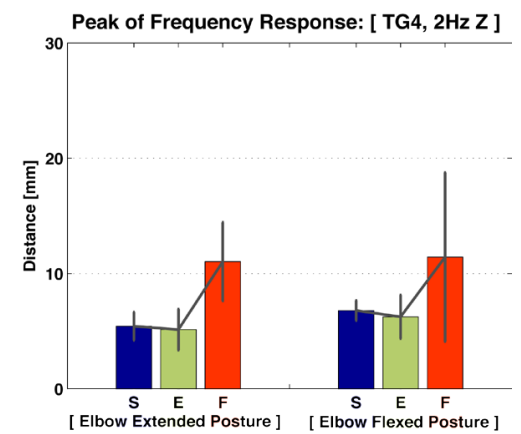

(a) $2 \mathrm{~Hz}$ vertical vibration

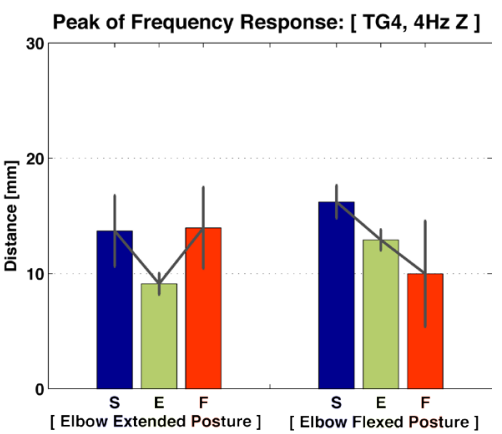

(b) $4 \mathrm{~Hz}$ vertical vibration

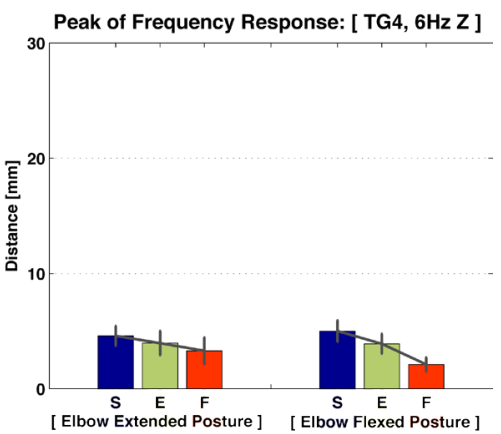

(c) $6 \mathrm{~Hz}$ vertical vibration

Figure 2: Vibration responses through the upper limb with elbow extended and flexed postures during forward-lateral reach [TG 4]: superscripts S: shoulder, E: elbow, F: fingertip

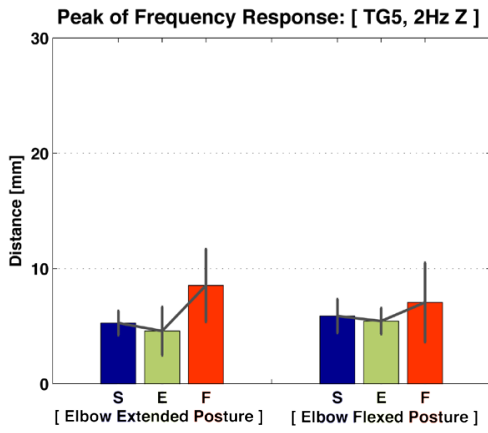

(a) $2 \mathrm{~Hz}$ vertical vibration

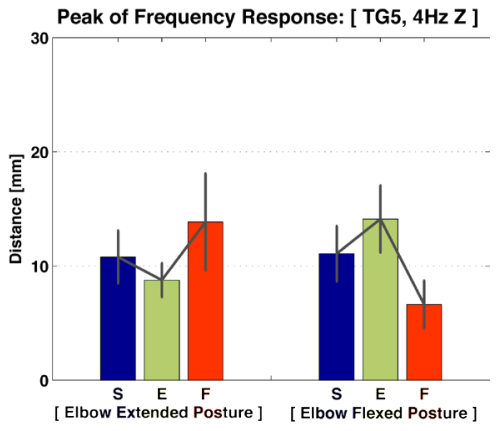

(b) $4 \mathrm{~Hz}$ vertical vibration

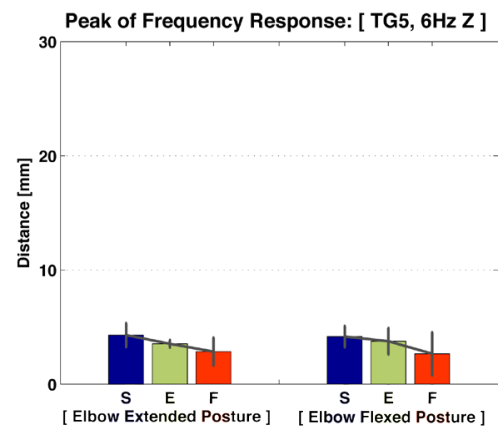

(c) $6 \mathrm{~Hz}$ vertical vibration

Figure 3: Vibration responses through the upper limb with elbow extended and flexed postures during diagonal-upward reach [TG 5]: superscripts S: shoulder, E: elbow, F: fingertip

\section{References}

1. Griffin, M.J. (1990). Handbook of human vibration. San Diego, Academic press.

2. Okunribido, O,O., Shimbles, S.J., Magnusson, M., and Pope, M. (2007). City bus driving and low back pain: A study of the exposure to posture demands, manual materials handling and whole-body vibration. Applied Ergonomics 38, 29-38.

3. Lim, S.H., Martin, B.J., and Chung, M.K., (2004). The effects of target location on temporal coordination of the upper body during $3 \mathrm{D}$ seated reaches considering the range of motion. International J. Industrial Ergonomics 34, 395-405.

4. Kim, H.J., and Martin, B.J. (2008). Three-dimensional joint kinematics of the upper exteremity in reach movements under whole-body vibraiton exposure. Human Factors and Ergonomic Society 52 ${ }^{\text {nd }}$ Annual Meeting. 52(15), 1000-1004. 